\title{
Quantifying ambivalence towards sustainable intensification: an exploration of the UK public's values
}

\author{
Andrew P. Barnes ${ }^{1}$ • Amanda Lucas ${ }^{2} \cdot$ Gregory Maio $^{3}$ \\ Received: 7 April 2015 / Accepted: 28 February 2016/Published online: 23 April 2016 \\ (C) The Author(s) 2016. This article is published with open access at Springerlink.com
}

\begin{abstract}
Sustainable intensification (SI) has been proposed as a solution to meeting the challenge of feeding a growing global population under increasing land pressure. This paper explores the level of ambivalence felt towards SI and towards experts promoting SI based solutions to meet food security. A web-based experiment was conducted with 600 respondents who had varying degrees of knowledge about food security issues. We found a diversity of public ambivalence towards sustainable intensification and a high level of felt ambivalence towards experts promoting SI as a solution to global food security. High levels of ambivalence towards experts seemed to influence how messages on global food security were accepted. Moreover, within the respondents here sustainable consumption and greater equity ranked higher than production based sustainable intensification solutions. This paper represents the first application of the psychological construct of ambivalence applied to the topic of sustainable intensification and we argue this helps to localise the debate around SI as it offers the opportunity to capture or disentangle responses towards food security issues.
\end{abstract}

Keywords Sustainable intensification · Aambivalence · Ordinal logisitic regression

Andrew P. Barnes

Andrew.Barnes@sruc.ac.uk

1 Land Economy, Environment and Society Group, SRUC, Kings Buildings, West Mains Road, Edinburgh EH9 3JG, UK

2 College of Life and Environmental Sciences, University of Exeter, Penryn TR10 9EZ, UK

3 School of Psychology, Cardiff University, Cardiff CF10 3AT, UK

\section{Introduction}

The political agenda towards food production has coalesced around securing supply in the face of future projected pressures on land availability from population growth and climate variability (Gregory et al. 2005; Godfrey et al. 2010; Geraldo et al. 2012). In response, a large body of scientific and policy literature has promoted the concept of 'sustainable intensification' (SI) (Royal Society 2009; Pollock et al. 2012; GOS, 2010; Rosegrant et al. 2014). There is no agreed definition of SI, but it commonly centres on sustainably producing food given a fixed, or declining, resource base. A range of studies has argued that the pursuit of SI will lead to trade-offs in economic, ecological and social dimensions of food production and consumption (Godfrey et al. 2010; Pretty et al. 2011; Conway 2011; Barnes 2012; Franks 2014; Barnes and Thomson 2014; McDonagh 2015; Godfray and Garnett 2014; Gadanakis et al. 2015). Accordingly, a number of authors have recognised that solutions badged as SI offer an emotive arena to debate future farming practices and food consumption pathways (Marsden 2010; Misselhorn et al. 2012; Garnett et al. 2013; Bos et al. 2013; Scarpellini et al. 2013).

Within the UK a research platform has been established by Defra on SI, and a significant tranche of funding for the UK Agri-Technology strategy is centred on the goal of sustainable intensification (Department for Business, Innovation and Skills 2013). The search for a technological fix has led opponents to argue that this does not address the inefficiencies within the supply chain and would have negative redistributive effects on the primary sector (Tomlinson 2013; McDonagh 2015) or have even tended to refer to sustainable intensification as an oxymoron (Marsden 2010; Lewis-Brown and Lymbery 2012). 
These views reflect a wider discomfort with productionistled approaches. Some scholars instead argue for a focus on possible alternatives, such as reconciling production with consumption, better food distribution, reducing inequity of food access, and the use of agro-ecological practices to boost productivity (IAASTD 2009; Horlings and Marsden 2011; Sage 2012; Hanspach et al. 2013; McDonagh 2015).

Regardless of these views there is some agreement that the food system requires behavioural change both within the production and consumption aspects of the food chain (Pretty et al. 2010; Sage 2012; Smith 2013). In addition, whilst some studies have focused on the public's attitude toward food security (for example TNS 2012) they have not addressed the issue of ambivalence. Within the psychology literature, ambivalence is a well-tested concept (Breckler 1994; Cacioppo and Berntson 1994; Green and Goldfried 1965). Studies have tended to focus on the ambivalence which emerges through opposing values but also from opposing opinions (Priester and Petty 1996; Sawicki et al. 2013; Gebauer et al. 2013). Ambivalence is a significant driver in shaping individual attitudes towards food related subjects such as attitudes towards meat consumption (Berndsen and van der Pligt 2004); vegetarianism and veganism (Povey et al. 2001); as well production related aspects of food, such as nanotechnology and acceptance of GMOs (Saher et al. 2006; Fischer et al. 2013). Overall, these studies find strong evidence of attitudinal ambivalence towards food and related technologies towards food production. Attitudinal ambivalence is based on individuals having both positive and negative evaluations towards an object, a behaviour or an issue at the same time (Thompson and Zanna 1995; Thompson, et al. 1995; Berndsen and van der Pligt 2004). Consequently, individuals can hold attitudes that are favourable and unfavourable. This can stem from many sources and, in the context of sustainable intensification, the conflict between relevant values and opinions towards food production and consumption is a likely source. These conflicts may emerge from understanding and belief towards the technology or its application to the rural sector (Barnes and Toma 2012; Tomlinson 2013; Vandermoere et al. 2010), or moreover, may be based on limited or contradictory statements towards food security (Fischer et al. 2013).

It may be that people will feel ambivalence towards those individuals who show traits that express opposing motivations rather than to individuals whose traits are similar or congruent. Crucially, this emerges even when the opposing traits are beliefs which are very positively regarded (Maio 2010; Gebauer et al. 2013). Accordingly, ambivalence is dictated not only by the terms themselves but by how experts are viewed when presenting the term, such as named experts in food security, agricultural scientists, representatives of the food chain, policy makers and representatives of governing institutions and NGOs. In relation to this, Petersen and Snapp (2015) found that experts within the food security realm demonstrated divergent opinions towards what they believed sustainable intensification to be and which technologies, e.g. organic agriculture, conservation agriculture, can be defined as part of SI.

Ambivalence may also lead to the selective rejection of persuasive messages (Clark et al. 2008; Sawicki et al. 2013). The response of society can limit the development of food related technologies. Accordingly, understanding what shapes public response to these approaches will be an integral part of forming a research strategy and ensuring the visibility and transparency of these techniques within the food supply chain (Ward and Barnes 2001; Fischer et al. 2013). In so doing it further presents opportunities for re-examining how food security agendas are promoted.

The first aim of the paper is to measure individuals' attitudes to Intensification and Sustainability as separate terms, in order to discover if there is any conflict between the two (henceforth referred to as 'intercomponent ambivalence'). The second aim is to characterise the feelings that individuals have towards experts promoting SI, in terms of their attitude favourability and felt ambivalence. Once constructed these measures are used to predict an individual's likelihood of choosing statements related to SI against a number of other food security related messages. This paper is structured as follows. The next section outlines the survey instrument and the methodology for analysis. Data and analysis of relationships are then presented within the results section. This is followed by a discussion of issues highlighted from this work and conclusions are drawn for both policy and research.

\section{Methodology}

\section{Data collection procedure}

A questionnaire was designed using on-line software. Data were collected through a UK based market research company who hold a standing panel of individuals and whose demographic and socio-demographic information is recorded. The panel consists of around 5,000 participants and a range of sampling techniques are used to maintain a representative panel in terms of age, income and regional distribution. Consequently, the use of this panel allowed representative sampling of age, gender and income grouping within the UK.

A total of 712 participants attempted the online questionnaire. However, 112 did not fully complete the questionnaire and were removed from analysis due to (a) failure to complete the values section satisfactorily (i.e. choosing 'none of the above' for all or nearly all of the terms) or (b) failure to 
complete the rating scales satisfactorily (i.e., rating all or nearly all of the terms or experts with the same numerical value).

Participants were then asked to rate on a scale of $0-6$ (where 0 indicated 'not at all' and 6 indicated 'very much') how knowledgeable they believed themselves to be about the issue of food security. Figure 1 shows the spread by age categories and self-rated knowledge around food security issues, indicating little difference across age-bands with only those in the oldest age group having lower self-ratings than the other groups.

As background, participants were first shown a picture of the front cover of the Foresight report on the Future of Food and Farming (Foresight 2011). This report was chosen as the key document in UK policy to create a significant change in awareness towards food security. It compiled evidence and forecasts on future food production and promoted the term sustainable intensification as a solution to this predicted crisis. Participants were provided with a photograph and quotation from Sir John Beddington, Government Chief Scientific Adviser at the time of the report's publication, which outlines the global food security crisis. They were also provided with the five key goals that the Foresight report asserted need to be addressed in order to achieve global food security. These were accompanied by some illustrative photographs taken from the report.

\section{Measuring ambivalence}

We measure individual ambivalence based on conflict within personal values. Schwartz (1992) defines values as "goals, varying in importance that serve as guiding principles in the life of a person". A body of research shows that there can be tension between sets of values (Schwartz 1992, 1994a, b; Maio et al. 2000; Vohs et al., 2006; Maio 2010; Evans et al. 2013). Effectively,

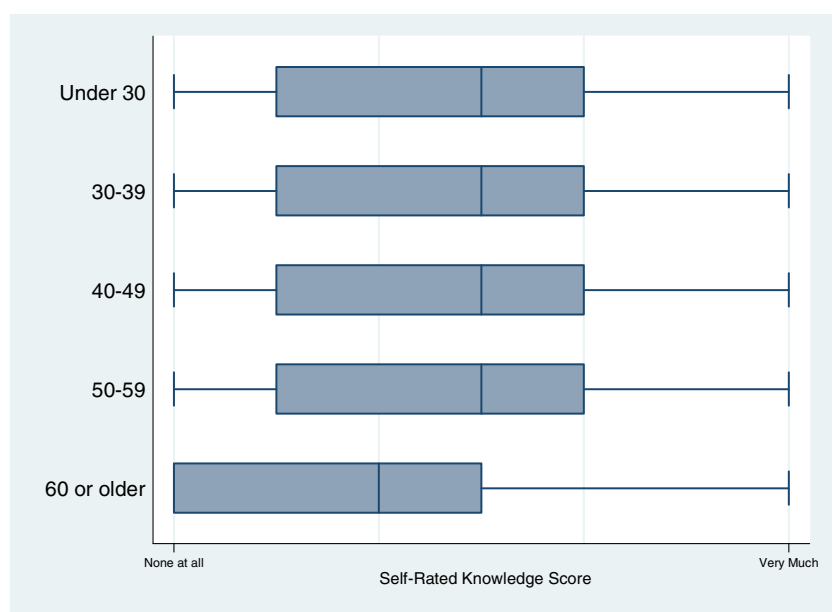

Fig. 1 Self-rated knowledge score about food security, by age individuals who place more weight on values within one domain (e.g. self-enhancement, comprising values such as achievement, success and power), place less on the other (e.g., self-transcendence, comprising values such as universalism and benevolence) or vice-versa (Bardi et al. 2009a, b; Schwartz et al. 2012). Accordingly, from this literature it seems reasonable to suggest that terms such as 'sustainable' might promote self-transcendence values whilst 'intensification' might elicit self-enhancement values. Thus, whilst both 'sustainable' and 'intensification' may be viewed as positive terms by individuals, they could represent opposing values and hence together this may result in feelings of ambivalence. In order to test this, individual value-based ambivalence can be measured as 'intercomponent ambivalence'.

Intercomponent ambivalence reflects the conflict between different components, i.e. sustainability and intensification. Participants were presented with 10 words associated with food security solutions or policy goals. Two of these were the target words - 'sustainability' and 'intensification'. The remaining eight were filler words identified as most frequently associated with food security in the Foresight report (Foresight 2011). Where it was felt necessary, a word was given a definition in brackets. ${ }^{1}$ Respondents were given the oppourtunity to respond with their thoughts at the end of the survey. A textual analysis of these responses using qualitative coding of words and phrases did not reveal any topics which were not covered in the list chosen for this study. These words are presented in Table 1.

Participants were presented with the words in a list on the same page. They were asked to rate how important each one was in developing policy solutions to achieving global food security. The scale extended from -3 (indicating 'Extremely Detrimental to developing policy solutions to global food security') via 0 (indicating 'Not Important') to +3 (indicating 'Extremely Important to developing policy solutions to global food security'). The order of the words in the list was randomised for each participant. Hence the positive and negative ratings were summed together to compute an overall net score for beliefs towards the items 'sustainability' and 'intensification'. Then the formula for intercomponent ambivalence was applied:

$|S|+|I|-2|S+I|+72$

Where $\mathrm{S}$ is the absolute net rating for sustainability, $\mathrm{I}$ is the absolute net rating for intensification and 72 is a constant added to avoid negative scores (see Maio et al. 1997, 2000).

\footnotetext{
${ }^{1}$ The survey was piloted on a small number of each of the target audiences within Scotland.
} 
Table 1 Ten words associated with global food security solutions

Words associated with creating food security (with definitions in parentheses, where appropriate)

Sustainability

Intensification

Productivity

Organic

Community

Modification (e.g., genetic)

Biodiversity (the variety of life in a particular habitat)

Efficiency

Biotechnology (the technological enhancement of living organisms to improve yield, nutrition, taste or resilience)

Behaviour-change (e.g., changing our diets to reduce pressure on the world's resources)

\section{Attitude favourability and felt ambivalence}

The level of attitude favourability towards SI in the food security context was next examined. Participants were informed that five experts had been asked to identify the two most important considerations in developing global food security. These experts were depicted as faceless heads and shoulder images, which differed only in the colour of their clothing and whether or not they were wearing a tie. Each expert was depicted with a speech bubble, in which was written the wording, 'The two most important considerations for developing global food security are [blank] and [blank]'. For one of the experts the two blanks were 'sustainability' and 'intensification'(See Fig. 2). For the remaining four experts, the blanks were randomly selected from the remaining eight filler words. Each expert was displayed on a separate page above the question 'How much do you agree with this statement?' Participants rated how much they agreed on an 11 point scale, whereby 0 indicated 'Completely Disagree' and 10 indicated 'Completely Agree'.

Then participants were asked to rate their ambivalence to these statements, defined as experiencing 'both negative and positive attitudes or feelings at the same time'. The same

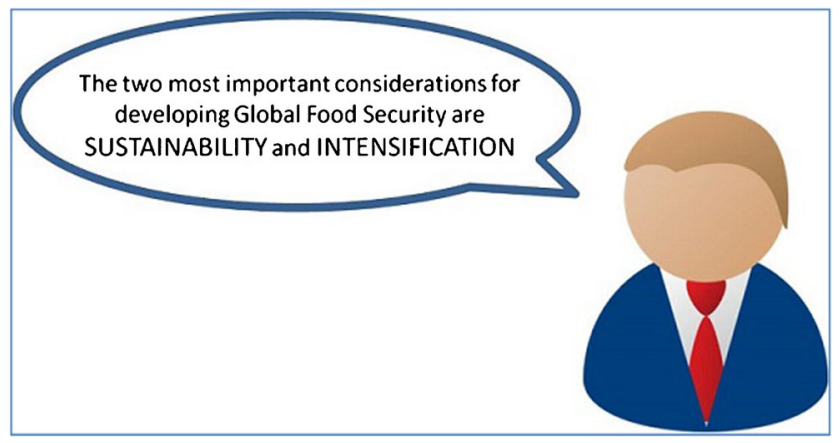

Fig. 2 Web Based Graphic for measuring attitude favourability experts as in the previous section were presented on separate pages and individuals were invited to rate their ambivalence to their statements on an 11 point scale, whereby 0 indicated 'No conflict. My attitude is either completely negative or completely positive' and 10 indicated 'Maximum conflict. I have both negative and positive attitudes towards this statement'.

\section{Selection of messages pertaining to SI}

Finally, a question relating to the search for information on food security provided by experts was explored. Participants were informed that, 'Sustainable Intensification in agriculture has been heralded by several high profile reports as forming a major part of the solution to achieving global food security. However this policy goal has also attracted controversy and criticism'. They were also told that eight more experts had been asked to give their opinion on the topic of sustainable intensification. Participants were instructed to look through the eight expert opinions and choose two that they would most like to read more of. These eight opinions are displayed in Table 2. Two were designed to argue for sustainable intensification, two for sustainability, two for intensification, and two for behaviour change/political change solutions. The order of presentation of these opinions was randomised for each participant.

After completing the questionnaire participants were asked if they wished to provide their own written opinion on creating global food security. Following this they were provided with a debrief explaining the aims of the experiment.

\section{Modelling framework}

There are two aspects of ambivalence that are of interest to us. Firstly, the role of intercomponent ambivalence on felt ambivalence. That is how much ambivalence towards experts promoting sustainable intensification is predicted by ambivalence towards the objects 'sustainable and 'intensification'. This was performed through ordinal regression, as the scales for dependant variables indicated progressive levels of felt

\footnotetext{
${ }^{2}$ In line with a tripartite model of attitudes, previous studies of ambivalence (e.g., Priester and Petty 1996; Sawicki et al. 2013) have measured ambivalence by summing three questions that access a participant's conflict, mixed negative and positive feelings, and indecision towards an attitude object. Pilot testing of the present survey found that participants experienced some frustration at being asked to complete three ambivalence questions for each expert. This is likely due to the nature of webbased surveys, whereby participants may not have the same commitment as those who have registered to take part in a psychology experiment. Thus, to make the survey more user-friendly, the measurement of ambivalence was reduced to a single rating as described.
} 
Table 2 Persuasive arguments in favour of sustainability, intensification, sustainable intensification and behaviour/ political change

\begin{tabular}{|c|c|}
\hline Normative Term & Persuasive Text \\
\hline Sustainability & $\begin{array}{l}\text { At the centre of sustainable agriculture should be the wise, } \\
\text { informed farmer who will start to move from agribusiness } \\
\text { to husbandry and conservation. Farmers will need to } \\
\text { become smaller scaled... } \\
\text { The ultimate aim of agricultural sustainability should be to } \\
\text { develop less intensive small-scale farming systems that } \\
\text { are very similar to natural ecosystems and that match } \\
\text { local conditions... }\end{array}$ \\
\hline Intensification & $\begin{array}{l}\text { The answer to [food security] is clearly increased productivity, } \\
\text { and in the situation where demand exceeds supply, crop } \\
\text { productivity must also be recognised as a significant } \\
\text { consumer benefit... } \\
\text { The claim that there is enough food in the world, but it needs } \\
\text { better redistribution carries some weight but it requires a } \\
\text { global Utopia that will not be realised... }\end{array}$ \\
\hline $\begin{array}{l}\text { Sustainable } \\
\text { Intensification }\end{array}$ & $\begin{array}{l}\text { Eco-efficient farming systems will need to be highly productive, } \\
\text { relying on clean energy sources and using environmentally } \\
\text { favourable industrial processes... } \\
\text { Key crops in some regions of the world reach only } 20 \% \text { of the } \\
\text { level of productivity enjoyed elsewhere. Closing only half of } \\
\text { that gap in yield through intensification would revolutionise the } \\
\text { relationship between agriculture and biodiversity, as well as } \\
\text { alleviate poverty... }\end{array}$ \\
\hline Behaviour/Political Change & $\begin{array}{l}\text { The greatest problems of food shortage are not the result of } \\
\text { limited global food production, but of poverty and poor } \\
\text { distribution. There is a need for a new equitable paradigm } \\
\text { of food production and consumption globally... } \\
\text { In the developed world we need to change what we put on our } \\
\text { plates, and the Western diet should not be exported to the rest } \\
\text { of the world: it's not sustainable, healthy or affordable... }\end{array}$ \\
\hline
\end{tabular}

ambivalence, which therefore equates to ordinal ranking of the data. Thus we take the standard form of the ordinal logistic regression models (Rabe-Hesketh et al. 2005):

$\operatorname{In}\left(\theta_{j}\right)=\alpha_{j}-x \beta_{t}$

where $\theta_{j}$ is the probability of a favourability score of $j$ against the probability of a favourability score greater than $j ; x$ are the $1 \ldots t$ independent variables, and $\alpha$ and $\beta$ are intercept and parameter effects respectively. Secondly, felt ambivalence was then used to predict the likelihood of selection or rejection of messages favourable to SI. The dependent variable was constructed as the choice related to choosing either of the two messages related to sustainable intensification. The dependent variable then becomes an ordinal ranking of $(0)$ where an individual could choose none of the messages, (1) at least 1 of the messages, (2) if both messages were chosen. Hence, we also apply the same ordinal logistic regression structure as this implies a ranking of message selection towards SI. This approach provides ease of interpretation, as it gives the cumulative odds of the effect of higher levels of ambivalence against a reference class, namely non-selection of messages concerning sustainable intensification.
All explanatory variables were continuous, reflecting different dimensions of ambivalence, aside from self-rated knowledge towards food security, which was handled as a dummy variable reflecting increased self-rated knowledge, with little or no knowledge of food security as a reference class. Estimation was conducted within Stata 13.1 (Stata Corp 2011).

\section{Results}

\section{Descriptives}

Table 3 shows the descriptive statistics for the various indices of ambivalence measured from the total responses.

Table 3 Descriptive statistics for ambivalence indices

\begin{tabular}{lrlll}
\hline Index & Mean & Std. Dev. & Min & Max \\
\hline Intercomponent ambivalence & 68.1 & 1.4 & 66.0 & 72.0 \\
Attitude favourability & 6.6 & 2.2 & 0 & 10 \\
Felt ambivalence & 5.4 & 3.1 & 0 & 10 \\
\hline
\end{tabular}


Attitude favourability is a simple measure of how favourable individuals were to an expert promoting SI for meeting global food security. Felt ambivalence explores how conflicted they were towards this expert. Over $50 \%$ of the sample had a high level of agreement with the expert statement towards SI but a similar number stated they were also highly conflicted (defined as "Maximum conflict. I have both negative and positive attitudes towards this statement").

In relation to both items, $18 \%$ (105 respondents) of those who completely agreed with the expert statement were also highly conflicted, a further $18 \%$ (106 respondents) who were unsure of the statement were also highly conflicted, and a further $6 \%$ (47 respondents) who completely disagreed with the statement were also highly conflicted.

Table 4 shows the inter-correlations between these components. Signs are as expected. Intercomponent ambivalence is negatively correlated with attitude favourability $(\mathrm{r} .=-0.216$, $p<0.05$ ). This indicates that the higher the level of ambivalence then the less favourable individuals would feel towards the experts promoting SI. Attitude favourability is negatively related to felt ambivalence $(\mathrm{r} .=-0.389, p<0.05)$. This indicates that higher ambivalence towards an expert would lead to less favourability towards the SI message.

\section{Ambivalence as a selector of persuasive messages}

Table 5 shows the overall frequency for each persuasive message statement, ranked by popularity across the respondents.

Respondents' choice of statements was fairly evenly spread. The least popular related to intensification and sustainability separately, whereas the most popular captured elements of both behavioural and political change. Statements relating to sustainable intensification were ranked third most popular "Key crops in regions..." and sixth most popular "Eco-efficient farming systems will need to be highly productive..."

Table 6 shows the results of the logistic ordinal regression, showing estimates for the proportional odds and thresholds of the cuts for the felt ambivalence scores and the selective exposure towards sustainable intensification.

The first model shows the effect of various predictors on increasingly felt ambivalence. What emerges is that whilst

Table 4 Inter-correlations between ambivalence indices

\begin{tabular}{llll}
\hline & & Intercomponent & Attitude favourability \\
\hline 1 & Intercomponent & & \\
2 & Attitude favourability & $-0.216^{* * *}$ & \\
3 & Felt ambivalence & 0.023 & $-0.389 * * *$ \\
\hline$* p<0.05, * * p<0.01, * * * p<0.001$ &
\end{tabular}

attitude favourability has no significant effect at the lower levels on felt ambivalence, as would be expected, as favourability increases then its effect on felt ambivalence decreases and becomes significant. Hence, strong agreement towards sustainable intensification tends to lead to lower ambivalence.

Intercomponent ambivalence is a significant predictor but tends to be lower than 1 , this means that as agreement with the juxtaposition of the terms 'sustainable' and 'intensification' increases then felt ambivalence towards experts promoting SI decreases.

The second model shows predictors for selective exposure towards statements related to messages supporting sustainable intensification. This indicates that only felt ambivalence is a negative predictor of selective exposure. That is as ambivalence towards experts supporting SI increases then they are less likely to select messages around SI. Other factors that would be expected to be a predictor, such as favourability towards the topic of SI and knowledge of food security issues, do not seem to be related to preferring SI over non-SI messages. One study, by Sawicki et al. (2013), found that ambivalence resulted in the selective neglect of persuasive messages only when issue knowledge was low. This would be true for the self-rated knowledge score, however this was not significant at the $95 \%$ confidence level.

\section{Discussion and conclusion}

The UK Government has dedicated a significant resource towards food security at both national and international country levels (e.g. DEFRA 2013; DBIS, 2013). This is through no small part the influence of high profile scientific and industry expertise (e.g. Royal Society 2009; Foresight 2011). However, within the headline documents there has been a distinct focus on technological solutions, as oppose to those which address consumer behaviours, redistribution and reducing inequity for greater food access (Vermeulen et al. 2012; Fish et al. 2013; Maye and Kirwan 2013; Tomlinson 2013).

Negative perspectives towards sustainable intensification could be seen as reflective of a suspicion towards the techno-centric views promoted by the scientific community and industry towards food production (Sage 2012; McDonagh 2015). Poortinga and Pidgeon (2003) explored different dimensions of trust across five risk domains related to government and regulation. They found two common components related to both fairness and equity, but also scepticism towards how policies are brought about and enacted. They argued that the functioning of a society requires engagement by citizens offering critical views of these policies. What is also noticeable is that other perspectives on food security were being presented at the same time as the Foresight report, with a 
Table 5 Selective exposure to persuasive information, ranked by frequency of response

\begin{tabular}{|c|c|c|c|}
\hline Rank & $(\%)$ & Normative Term & Persuasive Text \\
\hline 1 & 19 & Behaviour/Political Change & There is a need for a new equitable paradigm of food production and consumption globally... \\
\hline 2 & 15 & Behaviour/Political Change & $\begin{array}{l}\text { In the developed world we need to change what we put on our plates, and the Western diet should not be } \\
\text { exported to the rest of the world: it's not sustainable, healthy or affordable... }\end{array}$ \\
\hline 3 & 13 & Sustainability & $\begin{array}{l}\text { The ultimate aim of agricultural sustainability should be to develop less intensive small-scale farming } \\
\text { systems that are very similar to natural ecosystems and that match local conditions... }\end{array}$ \\
\hline 4 & 13 & Sustainable Intensification & $\begin{array}{l}\text { Key crops in some regions of the world reach only } 20 \% \text { of the level of productivity enjoyed elsewhere. } \\
\text { Closing only half of that gap in yield through intensification would revolutionise the relationship } \\
\text { between agriculture and biodiversity, as well as alleviate poverty... }\end{array}$ \\
\hline 5 & 12 & Intensification & $\begin{array}{l}\text { The claim that there is enough food in the world, but it needs better redistribution carries some weight but it } \\
\text { requires a global Utopia that will not be realised... }\end{array}$ \\
\hline 6 & 9 & Sustainable Intensification & $\begin{array}{l}\text { The answer to [food security] is clearly increased productivity, and in the situation where demand exceeds } \\
\text { supply, crop productivity must also be recognised as a significant consumer benefit... }\end{array}$ \\
\hline 7 & 9 & Intensification & $\begin{array}{l}\text { Eco-efficient farming systems will need to be highly productive, relying on clean energy sources and using } \\
\text { environmentally favourable industrial processes... }\end{array}$ \\
\hline 8 & 8 & Sustainability & $\begin{array}{l}\text { At the centre of sustainable agriculture should be the wise, informed farmer who will start to move from } \\
\text { agribusiness to husbandry and conservation. Farmers will need to become smaller scaled... }\end{array}$ \\
\hline
\end{tabular}

more ecological or community focus (e.g. IAASTD 2009). Why this vision was marginalised in favour of those promoting SI is debatable but is an intriguing sideline to the food security agenda and could, arguably, be reflected in the lobbying powers of agricultural and scientific communities to promote a pragmatic solution to a predicted future crisis.
It is clear from our findings that there is a level of public ambivalence towards sustainable intensification. Hence, this aligns with the polarity of opinion expressed towards SI within scientific, social scientific and policy debate around solutions to meet food security goals, such as genetically modified foods. Godfray and

Table 6 Maximum likelihood estimates for proportional odds models on felt ambivalence and selective exposure, standard errors in brackets

\begin{tabular}{|c|c|c|c|c|c|c|c|}
\hline \multicolumn{4}{|c|}{ Proportional Odds Model: Felt Ambivalence } & \multicolumn{4}{|c|}{ Proportional Odds Model: Selective Exposure } \\
\hline Odds Ratios & & & & Odds Ratios & & & \\
\hline $\exp (\beta 2)$ & [Attitude favourability (weak)] & 0.519 & $\left(\begin{array}{lll}0.5 & 03\end{array}\right)$ & $\exp (\beta 2)$ & [Felt ambivalence] & $-0.106^{* * *}$ & $(0.029)$ \\
\hline & [Attitude favourability (average)] & 0.256 & $(0.184)$ & $\exp (\beta 3)$ & [Attitude favourability] & 0.040 & $(0.040)$ \\
\hline & [Attitude favourability (strong)] & $0.022 * * *$ & $(0.017)$ & $\exp (\beta 4)$ & [Knowledge of food security (low)] & -0.081 & $(0.296)$ \\
\hline $\exp (\beta 3)$ & [Intercomponent ambivalence] & $0.845^{* *}$ & $(0.046)$ & & [Knowledge of food security (ave)] & 0.234 & $(0.277)$ \\
\hline & & & & & [Knowledge of food security (high)] & 0.434 & $(0.428)$ \\
\hline Thresholds & & & & Thresholds & & & \\
\hline$\kappa_{1}$ & & -14.50 & & $\kappa_{1}$ & & -0.07 & \\
\hline$\kappa_{2}$ & & -13.68 & & $\kappa_{2}$ & & 3.09 & \\
\hline$\kappa_{3}$ & & -12.98 & & & & & \\
\hline$\kappa_{4}$ & & -12.63 & & & & & \\
\hline$\kappa_{5}$ & & -12.32 & & & & & \\
\hline$\kappa_{6}$ & & -11.65 & & & & & \\
\hline$\kappa_{7}$ & & -11.22 & & & & & \\
\hline$\kappa_{8}$ & & -10.76 & & & & & \\
\hline$\kappa_{9}$ & & -10.11 & & & & & \\
\hline$\kappa_{10}$ & & -9.38 & & & & & \\
\hline Log-Likelihood & & -1364.7 & & Log-Likelihood & & -480.1 & \\
\hline
\end{tabular}

$* p<0.05, * * p<0.01, * * * p<0.001$ 
Garnett (2014) contended that there is a missing balance between 'sustainable' and 'intensification' with SI. In quantifying this ambivalence effect it provides some argument for further research on the acceptability, the perceptions and the beliefs, which occur towards agricultural intensification.

A range of authors have tended to focus on widening or defining the parameters of the term sustainable, arguably as a way to re-emphasise the social consequences within SI compared to the more prominent and early focus on the environmental effects (e.g. Barnes 2012; Garnett et al. 2013). For example, Loos et al. (2014) argue that the current usage of SI inadequately addresses the central tenets of sustainability and call for 'a more holistic characterization and assessment of sustainable intensification'. Intensification has merited less debate over its meaning and this could partially be due to the numerous physical and financial metrics which have been used and are available for measuring intensification, such as stocking density or fertiliser cost per ha (e.g. Barnes and Thomson 2014; Bava et al. 2014) and therefore may be seen as a more grounded concept for natural and social sciences to accept. Nevertheless, Hanspach et al. (2013) argue that in meeting the goals of SI, agricultural intensification is effectively meaningless against the context of sustainable development and they attempted to align the conjoint terms of sustainable and intensification within an ecological and development framework. This paper has applied a more behavioural approach to the conjunction of these terms and an effect on creating ambivalence within individuals has also been found.

Consumer acceptance of solutions to meet the demands of food security are driven in part by their level of agreement and, also, the level of disagreement they feel towards the experts offering these solutions. Allied to this are observations by Tomlinson (2013) and McDonagh $(2013 ; 2015)$ - regarding the changing targets of the FAO food production increases - as having weakened this debate. Here we find ambivalence towards these experts is present and also stated by those who had a favourable response towards sustainable intensification.

High levels of ambivalence towards experts also seem to influence how we seek and accept messages on global food security. Moreover, within the respondents here it seems sustainable consumption and greater equity rank higher than sustainable intensification related solutions. Reconciling sustainable production and consumption is seen by Sage (2012) as a 'Faustian bargain', implying the lack of any alignment of alternative visions to meet food security challenges. In addition, there is an imbalance towards production led solutions within the literature with little thought towards addressing consumption issues, which are predominantly non-technical and mostly behavioural or structural.

This paper represents the first application of the psychological construct of ambivalence applied to the topic of sustainable intensification. As we find this to have a significant effect it must have implications in how attitudes towards food security issues are measured in the future. Ambivalence reflects the tension between opposing values or perspectives and would seem an important facet as discussion of food security moves forward to address changing consumption and production related behaviours. The approach outlined here has found ambivalence to be particularly strong, and this agrees with other studies centred on areas of food production and consumption that have raised particular controversies (Berndsen and van der Pligt 2004; Fischer et al. 2013). A methodological point is, therefore, that standard uni-dimensional techniques of attitude assessment (e.g. TNS 2012) seem increasingly inadequate at capturing or disentangling responses, which are either uncertain or apathetic towards food security issues. Moreover, there is further value in exploring ambivalence combining both quantitative and qualitative methodologies. The diversity of responses shown within this study merit further exploration and qualitative methodologies, which can elicit the more subtle differences in response to these messages, could be usefully employed to investigate ambivalence in conjunction with the survey presented here.

The resilience of agricultural systems is driven by both local and global level pressures on supply and demand and both of these different scales should be equally considered as part of the future sustainable vision for food and agricultural systems. However this more localised development of agricultural systems has merited less emphasis within the SI debate compared to the tranche of global level studies, which in some cases even ignore differences between developed and developing country systems (Barnes 2012).

We would therefore argue that these localised debates with respect to food security highlight the diversity of perspectives and magnifies the ambivalence towards these global ambitions for SI policy. Respecting this heterogeneity of response towards SI is central to understanding the resilience of agricultural production as food security embraces a range of dimensions (FAO, 2008). Sustainable intensification has until recently only been aimed at one of these dimensions, namely food availability, and recent attempts have tried to align the term with access, availability and stability. This implies 
a role for the social and psychological sciences to understand the influence of messages on food consumption and production decisions. The role of behaviour change in consumption is recognised as a driver for reducing carbon emissions (Smith 2013), hence minimising the dissonance observed here could encourage more engagement with food security issues if there were less prominence in the debate towards such 'grand technological solutions'.

Acknowledgments This research was supported by the Scottish Government Research Programme into Food and Economic Adaptation.

Open Access This article is distributed under the terms of the Creative Commons Attribution 4.0 International License (http:// creativecommons.org/licenses/by/4.0/), which permits unrestricted use, distribution, and reproduction in any medium, provided you give appropriate credit to the original author(s) and the source, provide a link to the Creative Commons license, and indicate if changes were made.

\section{References}

Bardi, A., Guerra, V. M., \& Ramdeney, S. (2009a). Openness and ambiguity intolerance, their differential relations to well-being in the context of an academic life transition. Personality and Individual Differences, 47, 219-223.

Bardi, A., Lee, J. A., Hofmann-Towfigh, N., \& Soutar, G. (2009b). The structure of intra-individual value change. Journal of Personality and Social Psychology, 97, 913-929.

Barnes, A. P. (2012). Sustainable intensification in Scottish agriculture: a discussion document. Report to the rural policy centre. Edinburgh: SRUC.

Barnes, A. P., \& Thomson, S. G. (2014). Deriving an index of sustainable intensification: how far can secondary data go. Ecological Indicators, 36, 213-220.

Barnes, A. P., \& Toma, L. (2012). A typology of dairy farmer perceptions towards climate change. Climatic Change, 112(2), 507-522.

Bava, L., Sandrucci, A., Zucali, M., Guerci, M., \& Tamburini, A. (2014). How can farming intensification affect the environmental impact of milk production? Journal of Dairy Science, 97(7), 4579-4593.

Berndsen, M., \& van der Pligt, J. (2004). Ambivalence towards meat. Appetite, 42, 71-78.

Bos, J. F. F. P., Bert, A., Smit, L., Jaap, J., \& Schröder, J. (2013). Is agricultural intensification in The Netherlands running up to its limits? Wageningen Journal of Life Sciences, 66, 65-73.

Breckler, S. J. (1994). A comparison of numerical indexes for measuring attitude ambivalence. Educational and Psychological Measurement, 54, 350-365.

Cacioppo, J. T., \& Berntson, G. G. (1994). Relationship between attitudes and evaluative space: a critical review, with emphasis on the separability of positive and negative substrates. Psychological Bulletin, $115,401-423$.

Clark, J. K., Wegener, D. T., \& Fabrigar, L. R. (2008). Attitudinal ambivalence and message-based persuasion, motivated processing of proattitudinal information and avoidance of counterattitudinal information. Personality and Social Psychology Bulletin, 34, 565-577.
Conway, G. (2011). Discussion Meeting on Reducing Greenhouse Gas Emissions from Agriculture, Meeting the Challenge of Food Security and Climate Change, 28th Feburary-1st March 2011. The Royal Society, London, 2011.

DEFRA, (2013). Sustainable Intensification. Working paper 8. Available at: https://www.gov.uk/government/uploads/system/uploads/ attachment_data/file/218814/Sust-Int-platform-working-paper8. pdf. Accessed on 6th April 2014.

Department for Business, Innovation and Skills. (2013). A UK strategy for agricultural technologies. London: HMSO.

Evans, L., Maio, G. R., Corner, A., Hodgetts, C. J., Ahmed, S., \& Hahn, U. (2013). Self-interest and pro-environmental behaviour. Nature Climate Change, 3, 122-125.

Fischer, A. R., van Dijk, H., de Jonge, J., Rowe, G., \& Frewer, L. J. (2013). Attitudes and attitudinal ambivalence change towards nanotechnology applied to food production. Public Understanding of Science, 22, 817-31.

Fish, R., Lobley, M., \& Winter, M. (2013). A license to produce? farmer interpretations of the new food security agenda. Journal of Rural Studies, 29, 40-49.

Food and Agriculture Organisation. (2008). An introduction to the basic concepts of food security (Food security information for action: practical guidelines). Rome: FAO.

Foresight. (2011). The future of food and farming: final project report, the government office for science. London: HMSO.

Franks, J. R. (2014). Sustainable intensification: a UK perspective. Food Policy, 47, 71-80.

Gadanakis, Y., Bennett, R., Park, J., \& Areal, F. J. (2015). Evaluating the sustainable intensification of arable farms. Journal of Environmental Management, 150, 288-298.

Garnett, T., et al. (2013). Sustainable intensification in agriculture, premises and policies. Science, 341, 33-34.

Gebauer, J. E., Maio, G. R., \& Pakizeh, A. (2013). Feeling torn when everything seems right value-based incongruence causes felt ambivalence. Personality and Social Psychology Bulletin, 39, 777-791.

Geraldo, M. B., Alves, E., \& Contini, E. (2012). Land-saving approaches and beef production growth in Brazil. Agricultural Systems, 110, 173-177.

Godfray, H. C. J., \& Garnett, T. (2014). Food security and sustainable intensification. Philosophical Transactions of the Royal Society B, $369,1-10$.

Godfrey, H. C., et al. (2010). Food security the challenge of feeding 9 billion people. Science, 327,812 .

Government Office for Science. (2010). The UK cross government strategy for food research and innovation. London: HMSO.

Green, R.F., Goldfried, M.R. (1965). On the bipolarity of semantic space. Psychological Monographs 79, (6), whole number 599).

Gregory, P. J., Ingram, J. S. I., \& Brklacichi, M. (2005). Climate change and food security. Philosophical Transactions of the Royal Society, B360, 2139-2148.

Hanspach, J., Abson, D. J., Loos, J., Tichit, M., Chappell, M. J., \& Fischer, J. (2013). Develop, then intensify. Science, 341, 713.

Horlings, L. \& Marsden, T. (2011) Towards a real green revolution: exploring the conceptual dimensions of a new ecological modernization of agriculture that could feed the world. Global Environmental Change, 21, 441-452.

IAASTD. (2009). Agriculture at a crossroads. Synthesis report produced by international assessment of agricultural knowledge science and technology for development. Conneticut: Island Press.

Lewis-Brown, E. \& Lymbery, P. (2012). Sustainable intensification-an oxymoron. Compassion in world farming: Available at: https:// www.ciwf.org.uk/includes/documents/cm_docs/2012/s/ 
sustainable_intensification_an_oxymoron.pdf. Accessed 4 Mar 2013.

Loos, J., Abson, D. J., Chappell, M. J., Hanspach, J., Mikulcak, F., Tichit, M., \& Fischer, J. (2014). Putting meaning back into "sustainable intensification". Frontiers in Ecology and the Environment, 12, $356-361$.

Maio, G. R. (2010). Mental representations of social values. Advances in Experimental Social Psychology, 42, 1-43.

Maio, G. R., Esses, V. M., \& Bell, D. W. (2000). Examining conflict between components of attitudes, ambivalence and inconsistency are distinct constructs. Canadian Journal of Behavioural Science, $32,58-70$.

Marsden, T. (2010). Food 2030, towards a redefinition of food? a commentary on the New United Kingdom government food strategy. Health Policy Quarterly, 81, 443-446.

Maye, D., \& Kirwan, J. (2013). Food security: a fractured consensus. Journal of Rural Studies, 29, 1-6.

McDonagh, J. (2013). Changing expectations and contradictions in the rural. Progress in Human Geography, 37(5), 712-720.

McDonagh, J. (2015). Rural geography III: Do we really have a choice? the bioeconomy and future rural pathways. Progress in Human Geography, 39, 658-665.

Misselhorn, A., Aggarwal, P., Ericksen, P., et al. (2012). A vision for attaining food security. Current Opinion in Environmental Sustainability, 4, 7-17.

Petersen, B., \& Snapp, S. (2015). What is sustainable intensification? views from experts. Land Use Policy, 46, 1-10.

Pollock et al. (2012). Feeding the Future: Innovation Requirements for Primary Food Production in the UK to 2030. Report of the Joint Commissioning Group. Agricultural and Horticultural Development Board, UK

Poortinga, W., \& Pidgeon, N. F. (2003). Exploring the dimensionality of trust in risk regulation. Risk Analysis, 23(5), 961-72.

Povey, R., Wellens, B., \& Conner, M. (2001). Attitudes towards following meat, vegetarian and vegan diets, an examination of the role of ambivalence. Appetite, 37, 15-26.

Pretty, J., Sutherland, W. J., Ashby, J., et al. (2010). The top 100 questions of importance to the future of global agriculture. International Journal of Agricultural Sustainability, 8, 219-236.

Pretty, J., Toulim, C., Williams, S. (2011). Sustainable Intensification, Increasing Productivity in African Food and Agricultural Systems. International Journal Agricultural Sustainability Series, Earthscan, 2011.

Priester, J., \& Petty, R. E. (1996). The gradual threshold model of ambivalence, relating the positive and negative bases of attitudes to subjective ambivalence. Journal of Personality and Social Psychology, $71,431-449$.

Rabe-Hesketh, S., Skrondal, A., \& Pickles, A. (2005). Maximum likelihood estimation of limited and discrete dependent variable models with nested random effects. Journal of Econometrics, 128, 301-323.

Rosegrant, M. W., Koo, J., Cenacchi, N., Ringler, C., Robertson, R., Fisher, M., Cox, C., Garrett, K., Perez, N. D., \& Sabbagh, P. (2014). Food security in a world of natural resource scarcity. Washington DC: International Food Policy Research Institute.

Royal Society, (2009). Reaping the benefits, Science and the sustainable intensification of global agriculture. RS Policy document 11/09. Royal Society, London, October 2009

Sage, C. (2012). Addressing the Faustian bargain of the modern food system, connecting sustainable agriculture with sustainable consumption. International Journal of Agricultural Sustainability, 10, 204-207.

Saher, M., Lindeman, M., \& Koivsto Hursti, U. K. K. (2006). Attitudes towards genetically modified and organic foods. Appetite, 46(3), 324-331.

Sawicki, V., Wegener, D. T., Clark, J. K., Fabrigar, L. R., Smith, S. M., \& Durso, G. R. (2013). Feeling conflicted and seeking information when ambivalence enhances and diminishes selective exposure to attitude-consistent information. Personality and Social Psychology Bulletin, 39, 735-747.

Scarpellini, E., Sassatelli, R., Banterle, A., \& Olperle, A. (2013). Essential SSH research for the societal challenge: food security, sustainable agriculture and forestry. Leuvan: League of European Research Universities.

Schwartz, S. H. (1992). Universals in the content and structure of values, theoretical advances and empirical tests in 20 countries. Advances in Experimental Social Psychology, 25, 1-65.

Schwartz, S. H. (1994a). Studying Human Values. In Bouvy, A.; Vijver, F.; Boski, P.; Schmitz, P. Journeys Into CrossCultural Psychology.,pp.. 239 - 254. Swets and Zeitlinger, Amsterdam

Schwartz, S. H. (1994b). Are there universal aspects in the structure and contents of human values? Journal of Social Issues, $50,19-45$.

Schwartz, S. H., Cieciuch, J., Vecchione, M., Davidov, E., Fischer, R., Beierlein, C., \& Demirutku, K. (2012). Refining the theory of basic individual values. Journal of Personality and Social Psychology, $103,663-688$

Smith, P. (2013). Delivering food security without increasing pressure on land. Global Food Security, 2, 18-23.

StataCorp. (2011). Stata statistical software, release 12. College Station: StataCorp LP.

Thompson, M. M., \& Zanna, M. P. (1995). The conflicted individual, personality-based and domain-specific antecedents of ambivalent social attitudes. Journal of Personality, 63, 259-88.

Thompson, M. M., Zanna, M. P., \& Griffin, D. W. (1995). Let's not be indifferent about (attitudinal) ambivalence. In R. E. Petty \& J. A. Krosnick (Eds.), Attitude strength: antecedents and consequences (pp. 361-386). Mahwah: Lawrence Erlbaum.

TNS (2012). Global Food Security Programme. A survey of public attitudes. Global Food Security Programme. Accessed on 14th March 2014. Available at: http://www.foodsecurity.ac.uk/assets/pdfs/gfssurvey-public-attitudes.pdf

Tomlinson, I. (2013). Doubling food production to feed the 9 billion, a critical perspective on a key discourse of food security in the UK. Journal of Rural Studies, 29, 81-90.

Vandermoere, F., Blanchemanche, S., Bieberstein, A., Marette, S., Roosen, J. (2010). The morality of attitudes toward nanotechnology: about god, techno-scientific progress, and interfering with nature. Journal of Nanoparticle Research, 12(2), 373-381.

Vermeulen, S. J., Campbell, B. M., \& Ingram, J. S. I. (2012). Climate change and food systems. Annual Review of Environment and Resources, 37, 195-222.

Vohs, K. D., Mead, N. L., \& Goode, M. R. (2006). The psychological consequences of money. Science, 314(5802), 1154-1156.

Ward, J. C., \& Barnes, J. W. (2001). Control and affect: theinfluence of feeling in control of the retail environment on affect, involvement, attitude, and behavior. Journal of Business Research, 54, 139-144. 


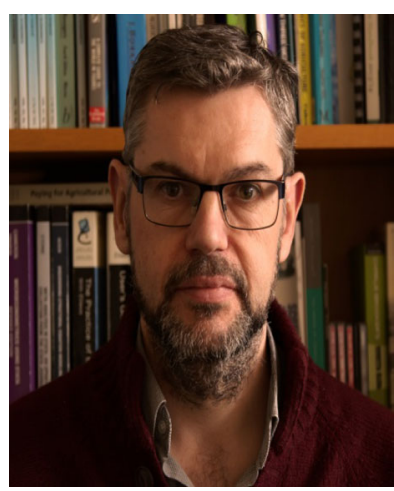

Dr Andrew Barnes is a Reader in Innovation and Behavioural Change at SRUC. He has a PhD in Agricultural Economics from the University of Glasgow and around 20 years experience working within research and policy related to agricultural production and agri-food supply chains.

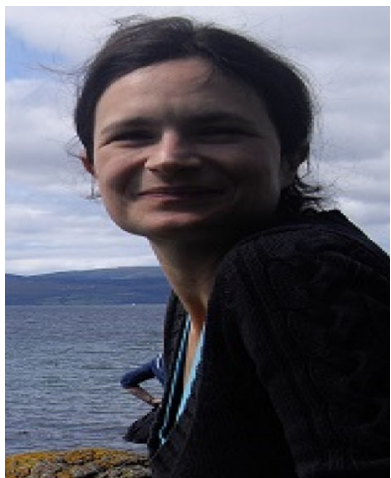

Dr Amanda Lucas conducts research into the transmission of culture at Exeter University. Previously she worked at the University of St Andrews, as well as SRUC specialising in the psychology of changing behaviours. Her PhD was gained at Lancaster University on the topic of the psychology of social learning.

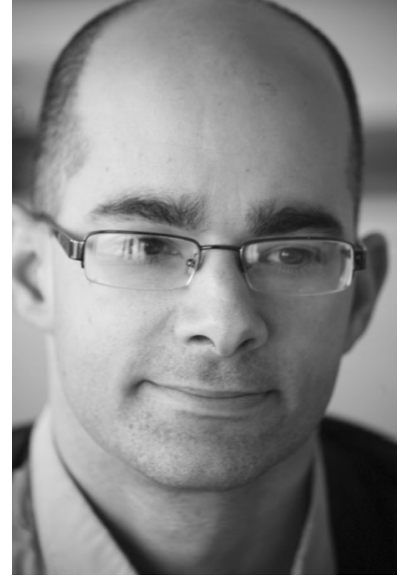

Prof Greg Maio is a social psychologist at Cardiff University. He has published widely on the topics of social values, attitudes, and behaviour. including "The Psychology of Attitudes and Attitude Change" (with G. Haddock, 2010, 2015) and "The Psychology of Values" (in press). 